\title{
Therapeutic Doses of Eltrombopag do not Inhibit Hepatic BCRP in Healthy Volunteers: Intravenous Ceftriaxone as a Model
}

\author{
Daniel Valente Neves, Carolina Pinto Vieira, Adriana Rocha and Vera Lucia Lanchote \\ Departamento de Análises Clínicas, Toxicológicas e Bromatológicas, Faculdade de Ciências Farmacêuticas de Ribeirão \\ Preto, Universidade de São Paulo, Ribeirão Preto, SP, Brazil.
}

Received, March 19, 2018; Revised, June 4, 2018; Accepted, June 21, 2018; Published, June 21, 2018.

\begin{abstract}
PURPOSE: Ceftriaxone elimination occurs through breast cancer resistance transporter (BCRP) and multidrug resistance-associated protein 2 (MRP-2) which are expressed on the canalicular membrane of hepatocytes. Eltrombopag, a thrombopoetin receptor agonist used in the treatment of immune thrombocytopenic purpura, is reported in in vitro studies as an inhibitor of intestinal BCRP but not an inhibitor of hepatic BCRP. Thus, the present study evaluates the effect of therapeutic doses of eltrombopag on the clinical pharmacokinetics of intravenous ceftriaxone. METHODS: Healthy adult $(n=12)$ were treated with oral doses of eltrombopag $(0,25 \mathrm{or} 50 \mathrm{mg}) 28$ and $4 \mathrm{~h}$ prior to intravenous ceftriaxone administration $(1 \mathrm{~g})$. Serial blood samples were collected up to $48 \mathrm{~h}$ after ceftriaxone administration and plasma samples were analysed by LC-MS/MS using $50 \mu \mathrm{L}$ aliquots (total concentration) and $100 \mu \mathrm{L}$ (unbound concentration). RESULTS: A method to analyze total and unbound ceftriaxone in plasma using LC-MS/MS was developed and validated with linearity from 1 to $200 \mu \mathrm{g} / \mathrm{mL}$. Both methods are sensitive, precise and accurate with coefficients of variation less than $15 \%$ in the study of inter- and intra-assay precision and accuracy. Ceftriaxone pharmacokinetics in healthy adults were described using a bicompartmental model, with a mean clearance of $0.96 \mathrm{~L} / \mathrm{h}\left(\mathrm{CI} 95 \%\right.$ 0.71-1.20) and $\mathrm{AUC}_{0-\infty}$ of $1106 \mu \mathrm{g} . \mathrm{h} / \mathrm{mL}$ (CI95\% 811-1400) for volunteers that received only ceftriaxone; clearance of $0.95 \mathrm{~L} / \mathrm{h}(\mathrm{CI} 95 \% 0.77-1.13)$ and $\mathrm{AUC}_{0-\infty}$ of $1083 \mu \mathrm{g} \cdot \mathrm{h} / \mathrm{mL}(\mathrm{CI} 95 \%$ 876-1290) for volunteers that received ceftriaxone plus $25 \mathrm{mg}$ of eltrombopag and clearance of $0.96 \mathrm{~L} / \mathrm{h}$ (CI95\% 0.74-1.19) and $\mathrm{AUC}_{0-\infty}$ of $1072 \mu \mathrm{g} . \mathrm{h} / \mathrm{mL}$ (CI95\% 872-1273) for volunteers that received ceftriaxone plus $50 \mathrm{mg}$ of eltrombopag. CONCLUSIONS: The results do not support the existence of a clinical pharmacokinetic drug interaction involving hepatic BCRP in human subjects receiving intravenous ceftriaxone and oral eltrombopag.
\end{abstract}

This article is open to POST-PUBLICATION REVIEW. Registered readers (see "For Readers") may comment by clicking on ABSTRACT on the issue's contents page.

\section{INTRODUCTION}

Breast cancer resistance protein (BCRP) is an efflux protein of importance in pharmacokinetics and in drug-drug interactions (DDI) with other inhibitory drugs or substrates of this protein $(1,2)$. BCRP is located in various tissues of humans, such as the intestine (apical brush border membrane of the enterocyte), liver (hepatocyte membrane canaliculi), kidneys (apical brush border membrane of proximal renal tubular cells), testis, placenta and blood-brain barrier, and its activity can affect the absorption and elimination of drugs that are substrates of this drug transporter $(2,3)$.

The clinical relevance of BCRP in drug disposition has been demonstrated in several pharmacogenetic studies investigating the cDNA polymorphism c.421C >A (Q141K, rs2231142), in which the transport function of this efflux protein is decreased (421CA or AA) and the plasma concentrations of several drugs, such as rosuvastatin and atorvastatin, are increased (4-6). Thus, inter-individual differences in BCRP function contribute to the variability in drug exposure and efficacy of drugs that are BCRP substrates (5). In addition to genetic polymorphism, concomitant administration of BCRP inhibitor drugs may also increase systemic exposure of BCRP substrates. Patients with solid tumors treated with oral topotecan with elacridar, an inhibitor of BCRP and P-glycoprotein (P-gp), showed a significant increase of the oral bioavailability of topotecan, from 40 to $97 \%$ (7).

Experimental studies have also investigated the potential role for BCRP in DDIs. Intravenous administration of methotrexate, a BCRP substrate, in Bcrpl knockout mice or in wild-type mice pre treated with pantoprazole, an inhibitor of BCRP -

Corresponding Author: Vera Lucia Lanchote, Faculdade de Ciências Farmacêuticas de Ribeirão Preto, USP, Departamento de Análises Clínicas, Toxicológicas e Bromatológicas, Av. do Café, s/n, Campus da USP, Ribeirão Preto, SP, Brasil; lanchote@fcfrp.usp.br 
and P-gp, reduced methotrexate clearance (1.5 vs $0.8 \mathrm{~L} / \mathrm{h} / \mathrm{kg}$ ) (8). Concomitant administration of eltrombopag $(75 \mathrm{md} /$ day for 5 days $)$ with rosuvastatin $10 \mathrm{mg}$ single oral dose increased plasma rosuvastatin exposure in healthy volunteers by $55 \%$. The study authors speculated that this effect could be due to eltrombopag inhibition of OATP1B1 (reducing the hepatic uptake) and/or BCRP (enhancing rosuvastatin absorption and/or by inhibiting rosuvastatin elimination in the bile) (9). Later, Takeuchi et al. (2014) showed that the plasma concentrations of oral rosuvastatin were much higher in Bcrpl knockout mice when compared to Bcrpl wild-type mice, but the difference between the two strains was not so marked after intravenous administration of rosuvastatin (10). The cited authors also showed that transcellular transport of rosuvastatin in the apical to basal direction across Madin-Darby canine kidney II/BCRP/PDZ domain-containing 1 (MDCKII/BCRP/PDZK1) cells was elevated in the presence of $10 \mu \mathrm{M}$ eltrombopag and similar to that across (MDCKII/mock/PDZK1) cells, demonstrating that eltrombopag is a high-affinity substrate for BCRP and a potent inhibitor of intestinal BCRP (10). Elsby et al. (2016) showed that eltrombopag inhibited BCRP-mediated rosuvastatin transport with $\mathrm{IC}_{50}$ value of $2.1 \mu \mathrm{M}$ in colorectal adenocarcinoma (Caco-2) cells BCRP inhibition assay utilizing rosuvastatin as BCRP probe substrate (6). Furthermore, eltrombopag was predicted to cause a DDI through intestinal BCRP inhibition in vivo (maximum theoretical gastrointestinal concentration/absolute inhibition constant ratio of 323), but not a DDI through hepatic BCRP inhibition in vivo (maximum unbound liver inlet concentration/absolute inhibition constant of 0.11), supporting that inhibition of intestinal BCRP may be the principal cause of the clinically observed BCRP-mediated DDIs. The cited authors reported that solitary inhibition of the intestinal BCRP by fostamatinib (100 mg twice daily for 5 days) increased up to a 2fold rosuvastatin exposure in healthy volunteers (6).

Ceftriaxone is a third generation cephalosporin used in the treatment of bacterial infections caused by susceptible gram-positive and gram-negative microorganisms (11). It is used in paediatric and adult patients in the treatment of various infections, such as urinary tract and respiratory tract infections, septicemia, meningitis and the treatment of nosocomial infections caused by multidrug resistant pathogens (12-15). Ceftriaxone is highly bound to plasma proteins (83-96\%) and eliminated in urine $(40-67 \%$ of dose) and bile as the unchanged drug. Ceftriaxone is one of the cephalosporins with the highest biliary elimination (40-50\% of the dose) compared to other betalactam antibiotics (16-18). The elimination of ceftriaxone through the biliary tract occurs through BCRP and MRP-2 (Multidrug ResistanceAssociated Protein-2), which are expressed in the hepatocyte canalicular membrane (19). Ceftriaxone is a hydrophilic drug $(\log \mathrm{P}=-2.1)$ with a volume of distribution of approximately $9 \mathrm{~L}$, an elimination half-life of $6.2 \mathrm{~h}$ and a total clearance of $1 \mathrm{~L} / \mathrm{h}$ in healthy adults $(16,20)$.

Eltrombopag is a thrombopoietin receptor agonist, indicated for oral use in the treatment of immune thrombocytopenic purpura (21). Hepatic uptake of eltrombopag, mediated at least in part by OATP1B1, is the rate-limiting process in its overall elimination. Eltrombopag can act as an inhibitor of OATP1B1 and also as a potent inhibitor of BCRP in the small intestine, with saturation being observed at around $10 \mu \mathrm{M}$, inferring that inhibition of BCRP by eltrombopag may occur at the clinical doses (10).

Results from pharmacokinetic modelling of in vitro studies predicted that orally administered eltrombopag will not inhibit hepatic BCRP (6); however, this prediction has not been tested clinically. The present study investigates for the first time in a clinical study, whether eltrombopag is also a hepatic BCRP inhibitor. Ceftriaxone was administered intravenously to healthy volunteers as a probe drug, since $40-50 \%$ of its elimination is biliary and dependent on hepatic BCRP. In addition, this study also reports the analysis of total and unbound ceftriaxone in small plasma aliquots $(150 \mu \mathrm{L})$ via LC-MS/MS.

\section{MATERIALS AND METHODS}

\section{Chemicals and reagents}

Ceftriaxone (ceftriaxone hemi-heptahydrate disodium salt, purity: 98\%) was purchased from Toronto Research Chemical (Ontario, Canada). Cefazolin was kindly supplied by Eli-Lilly (São Paulo, Brazil). The solvents and solutions used in the extraction procedures (acetonitrile (ACN), JT Baker, Xatoloc, Mexico; potassium phosphate monobasic $\left(\mathrm{KH}_{2} \mathrm{PO}_{4}\right)$, VETEC QUIMICA, SigmaAldrich, Brazil and chloroform, JT Baker, Phillipsburg, NJ, USA) and the mobile phase of the chromatographic system, were obtained from Merck (Darmstadt, Germany) as chromatography grade reagents. Diethylamine (JT Baker, Phillipsburg, NJ, USA) was PA grade. Water was obtained from the Milli-Q ${ }^{\circledR}$ Plus purification system (Millipore Corp., Bedford, MA, USA).

The stock solution of ceftriaxone was prepared at a concentration of $2000 \mu \mathrm{g}$ of the freebase $/ \mathrm{mL}$ of 
water. Working solutions were prepared by diluting the stock solution to the final concentrations of 2 , $8,16,40,80,160,240$ and $400 \mu \mathrm{g} / \mathrm{mL}$ water.

The internal standard solution (IS) of cefazolin was prepared at a concentration of $200 \mu \mathrm{g} / \mathrm{mL}$ of water. From this solution, dilution was performed to obtain a solution of $100 \mu \mathrm{g}$ of cefazolin $/ \mathrm{mL}$ water.

\section{Chromatographic analysis}

The HPLC system consisted of a Shimadzu chromatograph (Kyoto, Japan) equipped with an LC-10 AD pump and a CTO-10 AS oven. Ceftriaxone elution was performed on the Nova Pak ${ }^{\circledR}$ C18 column (Waters) with particles of $4 \mu \mathrm{m}$ $(150 \times 3.9 \mathrm{~mm})$ and the mobile phase ammonium acetate $\left(\mathrm{AcNH}_{4}\right)(10 \mathrm{mmol} / \mathrm{L}, \mathrm{pH} 6.57$ adjusted with diethylamine, $95 \%)$ : $\mathrm{ACN}(5 \%)$ with a flow rate of $1 \mathrm{~mL} / \mathrm{min}$ at $30{ }^{\circ} \mathrm{C}$.

The mass spectrometry detection system was the Quattro Micro LC triple quadrupole (Micromass, Manchester, UK) equipped with an electrospray interface (ESI). Analyses were performed in the positive ionization mode. The capillary voltage in the ESI was $3 \mathrm{kV}$. The source and desolvation temperatures were maintained at 150 and $280{ }^{\circ} \mathrm{C}$, respectively. Nitrogen was the nebulization gas at a release speed of $400 \mathrm{~L} / \mathrm{h}$, and argon was the collision gas at an approximate pressure of $2.00 \times 10-4 \mathrm{mbar}$. The cone voltage was kept at $15 \mathrm{~V}$ for ceftriaxone and $20 \mathrm{~V}$ for the IS. The collision energy was $15 \mathrm{eV}$ for ceftriaxone and IS.

Optimization conditions in MS/MS were obtained by the direct infusion of standard solutions of ceftriaxone (100 $\mu \mathrm{g} / \mathrm{mL}$ of water) and cefazolin $(100 \mu \mathrm{g} / \mathrm{mL}$ of water) incorporated in the mobile phase, through a diffusion pump that released $10 \mu \mathrm{L} / \mathrm{min}$. Analyses were conducted in the MRM mode (Multiple Reaction Monitoring).

Protonated ions $[\mathrm{M}+\mathrm{H}]^{+}$and respective ion products were monitored in transitions $554>396$ for ceftriaxone (see Fig. 1) and $455>323$ for IS (see Fig. 2). Data acquisition and sample quantification were performed with the MassLynx program, version 3.5 (Micromass, Manchester, UK).

\section{Sample preparation}

Blank plasma of healthy volunteers (not treated with ceftriaxone) were provided by the Hemocenter of the University Hospital, Faculty of Medicine, University of São Paulo, Brazil. For the analysis of total ceftriaxone, aliquots of $50 \mu \mathrm{L}$ of blank plasma (local hospital) spiked with $25 \mu \mathrm{L}$ of IS solution (cefazolin, $2.5 \mu \mathrm{g}$ ) were added to $25 \mu \mathrm{L}$ of water and $50 \mu \mathrm{L}$ of $\mathrm{KH}_{2} \mathrm{PO}_{4}$ buffer $(1 \mathrm{~mol} / \mathrm{L}, \mathrm{pH} 8.0)$ and precipitated with $200 \mu \mathrm{L}$ of acetonitrile. After shaking in the mixer ( $30 \mathrm{~s})$ and centrifugation at 10 $\min$ at $3000 \mathrm{~g}, 300 \mu \mathrm{L}$ of the supernatant was collected, and $100 \mu \mathrm{L}$ of chloroform was added. The tubes were again shaken in the mixer ( $30 \mathrm{~s}$ ), 70 $\mu \mathrm{L}$ of the supernatant was collected, and $40 \mu \mathrm{L}$ was submitted for analysis. For the analysis of unbound ceftriaxone, aliquots of $100 \mu \mathrm{L}$ of plasma were centrifuged in the Centrifree ${ }^{\circledR}$ device (Millipore Corporation, Billerica, MA, USA) for $80 \mathrm{~min}$, and $50 \mu \mathrm{L}$ aliquots of the ultrafiltrate were added to 200 $\mu \mathrm{L}$ of acetonitrile and $25 \mu \mathrm{L}$ of IS. After shaking in the mixer (30 s), $200 \mu \mathrm{L}$ of the supernatant was collected, and $60 \mu \mathrm{L}$ was submitted for analysis.

\section{Determination of the matrix effect}

The matrix effect was evaluated with 8 plasma samples, including 4 normal, 2 lipemic and 2 hemolyzed samples. Plasma samples were processed according to item sample preparation. The plasma extracts were spiked with the IS and with ceftriaxone at concentrations equivalent to low quality control (LQC) and high quality control (HQC). For each sample, the normalized matrix factor was calculated by the internal standard normalized matrix factor (ISTD), according to the following formula:

ISTD $=($ Analyte response in matrix/Response of internal standard in matrix)/(Response of analyte in solution/Response of internal standard in solution).

The results were expressed as coefficients of variation $(\mathrm{CV})$ of the ISTD for all samples, LQC and HQC. A matrix effect was considered absent if ISTD had a CV below $15 \%$.

\section{Validation}

The methods were validated according to the recommendations of the U.S. Food and Drug Administration guide for the industry in the validation of bioanalytical methods (22). To determine linearity, calibration curves were constructed by analyzing aliquots of $50 \mu \mathrm{L}$ of blank plasma for total ceftriaxone and $100 \mu \mathrm{L}$ of blank plasma for unbound ceftriaxone spiked with $25 \mu \mathrm{L}$ of each of the ceftriaxone solutions. Peak area ratios (analyte/IS) were plotted according to respective plasma concentrations $(1,4,8,20,40$, 80,120 and $200 \mu \mathrm{g}$ of unbound and total ceftriaxone per milliliter) with a weighting factor of $1 / \mathrm{X}$. The linear regression equations and the correlation coefficients were calculated.

The method was considered linear until the highest plasma concentration showed a deviation less than or equal to $15 \%$ of the nominal 
concentration and with a linear correlation coefficient equal to or greater than 0.98 .

The limit of quantification was defined as the lowest plasma concentration of ceftriaxone quantified with a precision of $20 \%$ and an accuracy of $80-120 \%$. Thus, 5 replicates were analyzed at the concentration of $1 \mu \mathrm{g}$ ceftriaxone/mL plasma.

Quality controls were prepared in blank plasma at concentrations of 1.0 (lower limit of quantification quality control-LLQC), 2.4 (low quality control-LQC), 80 (medium quality controlMQC), 160 (high quality control-HQC) and 1600 (dilution quality control-CQD) $\mu \mathrm{g}$ of ceftriaxone $/ \mathrm{mL}$ plasma.

Recovery was analyzed with blank plasma samples spiked with ceftriaxone (2.4 and 160 $\mu \mathrm{g} / \mathrm{mL}$ ) and IS. Recovery was calculated via the direct comparison of the peak areas of extracted samples with ceftriaxone standards peak areas and IS in solution, directly injected into LC-MS/MS.

The precision and accuracy of the methods were evaluated in intra- and inter-assay experiments. The plasma solution containing ceftriaxone was prepared using blank plasma spiked with ceftriaxone standard solutions at three different known concentrations: $2.4,80$ and $160 \mu \mathrm{g}$ of ceftriaxone $/ \mathrm{mL}$. Subsequently, aliquots of these solutions were stored at $-70^{\circ} \mathrm{C}$ until analysis. For the quantification of intra-run precision and accuracy, five aliquots of the concentrations mentioned above were analyzed in a single analytical assay and the results were calculated with a freshly prepared calibration curve. For the quantification of inter-assay precision and accuracy, five aliquots of the concentrations were analyzed on three consecutive days, and the results were calculated with a calibration curve newly prepared for each analytical run.

The dilution procedure was analyzed for samples originally above the upper limit of quantification. For this analysis, a $1600 \mu \mathrm{g} / \mathrm{mL}$ plasma solution was prepared similarly to the solutions mentioned above. A volume of $25 \mu \mathrm{L}$ of this plasma solution was added to $225 \mu \mathrm{L}$ of blank plasma (dilution 1 to 10). After homogenization for $30 \mathrm{~s}$ in vortex, $25 \mu \mathrm{L}$ of this diluted sample was processed as described in the sample preparation section.

To evaluate the stability of the samples, short duration, freeze-thaw and post-processing cycles were performed. For the evaluation of short-term stability, three aliquots of plasma ceftriaxone solution were kept at room temperature for $4 \mathrm{~h}$, after which time the samples were analyzed as described previously. For the evaluation of the stability of the freeze-thaw cycles, three aliquots of each solution were frozen at $-70{ }^{\circ} \mathrm{C}$ for $24 \mathrm{~h}$ and then thawed at room temperature. Successive cycles of freezing and thawing were performed and the samples were analyzed after the third cycle. For the evaluation of post-processing stability, extracts from three aliquots of ceftriaxone solution were maintained within the automatic injection system at $5 \pm 1^{\circ} \mathrm{C}$ for $12 \mathrm{~h}$ prior to LC-MS/MS injection. The results obtained were compared with those obtained by analyzing freshly prepared samples and expressed as relative standard error (\% inaccuracy).

\section{Clinical protocol}

The study was approved by the Research Ethics Committee of the Hospital das Clínicas of the Medical School of Ribeirão Preto, University of São Paulo, Brazil. The sample size was calculated with a Power and Sample Size Calculation program (23) using the AUC of ceftriaxone in healthy volunteers (AUC $1006 \mu \mathrm{g} . \mathrm{h} / \mathrm{ml}$, standard deviation $118 \mu \mathrm{g} . \mathrm{h} / \mathrm{mL}$ ) (24). The inclusion of 4 volunteers in each group resulted in a significance level of $\mathrm{p}$ $<0.05$, a test power of $80 \%$ and a difference between AUC means of at least 30\% (ceftriaxone vs. ceftriaxone $+25 \mathrm{mg}$ eltrombopag or ceftriaxone $+50 \mathrm{mg}$ eltrombopag).

This study enrolled twelve healthy adult volunteers. The volunteers were informed in detail about the study proposal, duration and possible risks involved. After signing the Informed Consent Term, the volunteers underwent clinical examination and laboratory tests to evaluate liver (ALT, AST, gamma GT, bilirubin and total proteins) and renal functions (urea, plasma creatinine and creatinine clearance (Cockroft-Gault formula)). After $8 \mathrm{~h}$ of fasting, the volunteers received a single intravascular dose of $1 \mathrm{~g}$ of ceftriaxone (at a concentration of $0.1 \mathrm{~g} / \mathrm{mL}$ by intravascular infusion for 3 minutes) (Rocefin ${ }^{\circledR}$, Roche, RJ, Brazil) with or without eltrombopag (Revolade, GlaxoSmithKline, RJ, Brazil). The studies were conducted in full compliance with the principles of the Helsinki Declaration and local laws and regulations related to clinical trials.

The clinical protocol consisted of 3 groups according to the presence (two different doses) or absence of eltrombopag. The first group $(n=4)$, after $12 \mathrm{~h}$ of fasting, received $1 \mathrm{~g}$ of ceftriaxone diluted in $10 \mathrm{~mL}$ of water in the morning (intravenous administration for 3 minutes). The second group $(n=4)$ was treated orally with two doses of $25 \mathrm{mg}$ of eltrombopag: the first dose was administered 28 hours prior to ceftriaxone administration, and the second dose was administered four hours prior to ceftriaxone administration. The third group $(n=4)$ was treated orally with two doses of $50 \mathrm{mg}$ of eltrombopag; the 
first dose was administered 28 hours prior to ceftriaxone administration, and the second dose was administered four hours prior to ceftriaxone administration. The standard hospital diet was served 3 hours after ceftriaxone administration. Blood samples $(5 \mathrm{~mL})$ were collected in heparinized syringes (Liquemine ${ }^{\circledR} 5000 \mathrm{IU}$, Roche) $0,0.5,1,2,4,8,12,18,24,32,40$ and 48 hours after the initiation of the ceftriaxone infusion. Plasma aliquots for chromatographic analysis were obtained by centrifugation of the blood samples (3000 g for $10 \mathrm{~min}$ ) and then stored at $-70^{\circ} \mathrm{C}$ until analysis.

\section{Pharmacokinetics and statistical analyses}

The pharmacokinetic analysis of ceftriaxone was performed with Phoenix ${ }^{\circledR}$ WinNonlin $^{\circledR}$, version 6.4 (Pharsight Corp, St Louis, MO, USA).
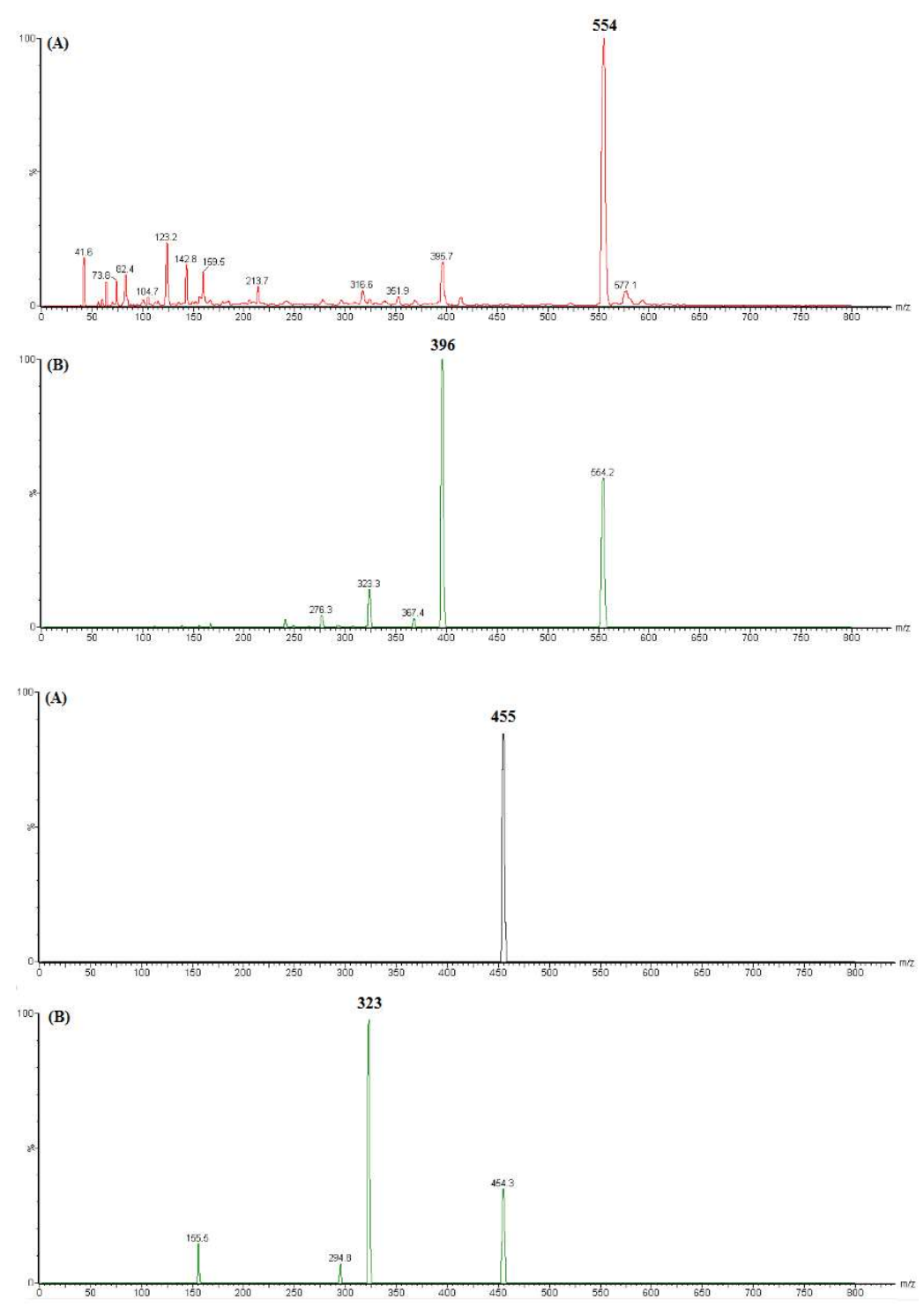

Pharmacokinetic parameters were calculated based on experimentally obtained plasma concentrations. Plasma concentration versus time data following the intravenous administration of ceftriaxone were analyzed based on the two-compartment model. Statistical analysis was performed, using ANOVA and Tukey post test and graphs were created with $\mathrm{R}$ (R Foundation for statistical computing, Vienna, Austria, 2014, version 3.1.2 R).

\section{RESULTS}

\section{Analysis of ceftriaxone in plasma}

Figures 1 and 2 show the protonated ions and their respective product ions monitored at transitions $554>396$ and $455>323$ for ceftriaxone and IS, respectively.

Figure 1. Mass spectra of the protonated molecular ion (A) and the product (B) ion of ceftriaxone.

Figure 2. Mass spectra of protonated molecular ion (A) and product (B) ion of cefazolin. 
Figure 3 shows the chromatograms related to the analysis of total ceftriaxone and Figure 4 shows the chromatograms related to the analysis of unbound ceftriaxone in healthy volunteer plasma $0.25 \mathrm{~h}$ after the administration of $1 \mathrm{~g}$ of ceftriaxone IV. The retention times for ceftriaxone and IS are shown in Table 1 as ceftriaxone total plasma concentration and as ceftriaxone unbound plasma concentration. Table 2 shows the ceftriaxone stability data as total plasma concentration.
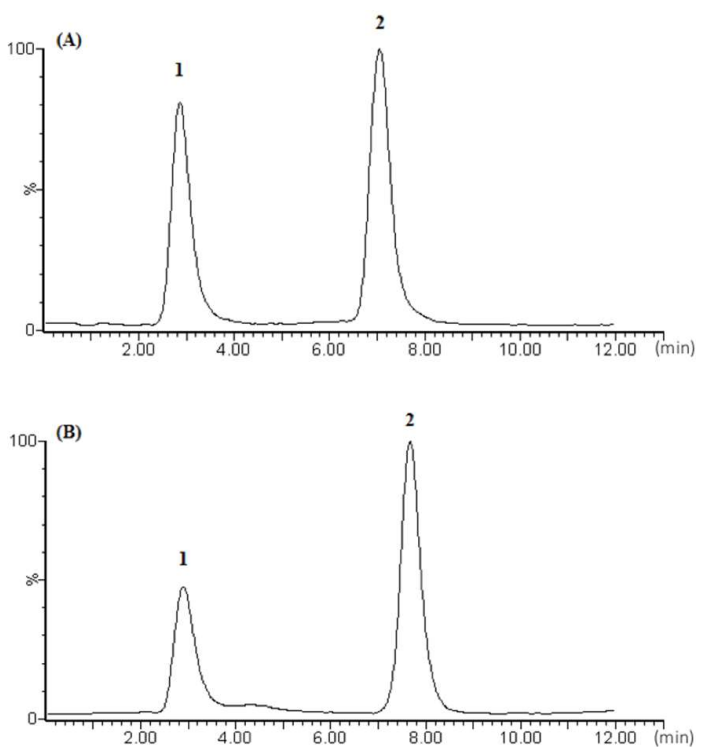

Figure 3. Chromatograms referring to the analysis of total plasma ceftriaxone. (A) Human plasma spiked with ceftriaxone $(200 \mu \mathrm{g} / \mathrm{mL})$ and cefazoline $(50 \mu \mathrm{g} / \mathrm{mL})$. (B) Plasma volunteer $0.25 \mathrm{~h}$ after administration of $1 \mathrm{~g}$ ceftriaxone IV. 1-ceftriaxone, 2-cefazoline

Table 1. Retention times of ceftriaxone and cefazolin when analysed as total and unbound plasma concentration

\begin{tabular}{llc}
\hline \multicolumn{1}{c}{ Drugs } & \multicolumn{2}{c}{ Retention time (min) } \\
& Total & Unbound \\
\cline { 2 - 3 } ceftriaxone & 2.85 & 1.10 \\
cefazolin (IS) & 7.62 & 1.12 \\
\hline
\end{tabular}

Table 3 depicts the validation data regarding total and unbound plasma ceftriaxone concentrations. Precision and accuracy results are acceptable for a quantification limit of $1 \mu \mathrm{g} / \mathrm{mL}$ plasma, linearity from 1 to $200 \mu \mathrm{g} / \mathrm{mL}$ plasma. The recovery of LQC $(2.4 \mu \mathrm{g} / \mathrm{mL})$ and HQC (160 $\mu \mathrm{g} / \mathrm{mL}$ ) ranged from $106-117 \%$, and IS recovery was approximately $107 \%$.
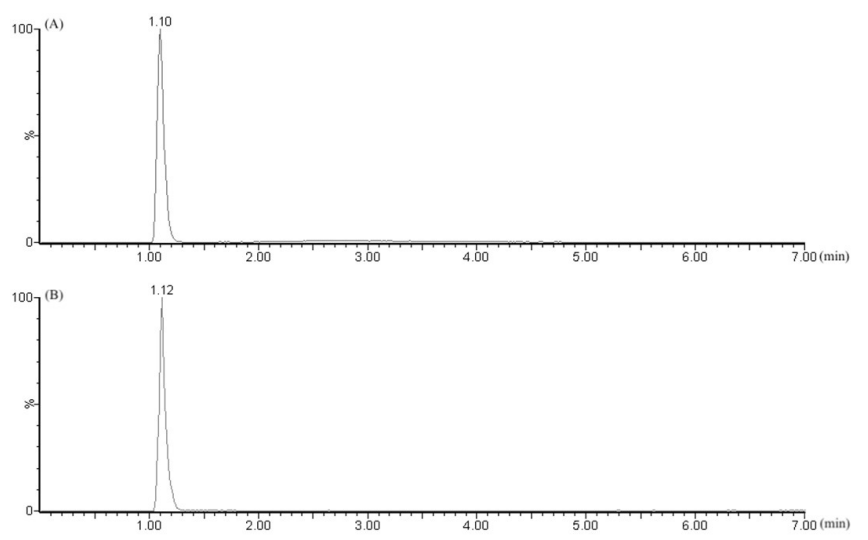

Figure 4. Chromatograms show the analysis of unbound ceftriaxone in plasma. Volunteer plasma $0.25 \mathrm{~h}$ after administration of $1 \mathrm{~g}$ ceftriaxone $\mathrm{IV}$, (A) ceftriaxone and (B) cefazoline (IS; $50 \mu \mathrm{g} / \mathrm{mL}$ ).

Table 2. Stability study of the analytical method of total plasma ceftriaxone concentration.

\begin{tabular}{l|c}
\hline Condition & \% Loss \\
\hline $4 \mathrm{~h}$ duration, & \\
$2.4 \mu \mathrm{g} / \mathrm{mL}$ & 2.38 \\
$160 \mu \mathrm{g} / \mathrm{mL}$ & 0.27 \\
Freezing $/$ thawing cycles & \\
$2.4 \mu \mathrm{g} / \mathrm{mL}$ & 2.20 \\
$160 \mu \mathrm{g} / \mathrm{mL}$ & 1.75 \\
Post-processing (12h) & \\
$2.4 \mu \mathrm{g} / \mathrm{mL}$ & 3.27 \\
$160 \mu \mathrm{g} / \mathrm{mL}$ & 6.42 \\
\hline
\end{tabular}

\section{Characteristics of volunteers}

The physical characteristics of volunteers are presented in Table 4 as the mean and 95\% CI. Age, weight, height, BMI and creatinine clearance values did not differ $(\mathrm{p} \leq 0.05)$ among the eltrombopag 0,25 and $50 \mathrm{mg}$ groups.

\section{Ceftriaxone pharmacokinetics}

The pharmacokinetics of total ceftriaxone are shown in Figure 5 (according to the use of eltrombopag) and in Table 5 (mean and 95\% CI). The data show similar pharmacokinetic parameters among the 3 groups (eltrombopag $0 \mathrm{mg}$, eltrombopag $25 \mathrm{mg}$, eltrombopag $50 \mathrm{mg}$ ). Table 5 shows the percentage of unbound ceftriaxone observed in 12 healthy volunteers. 


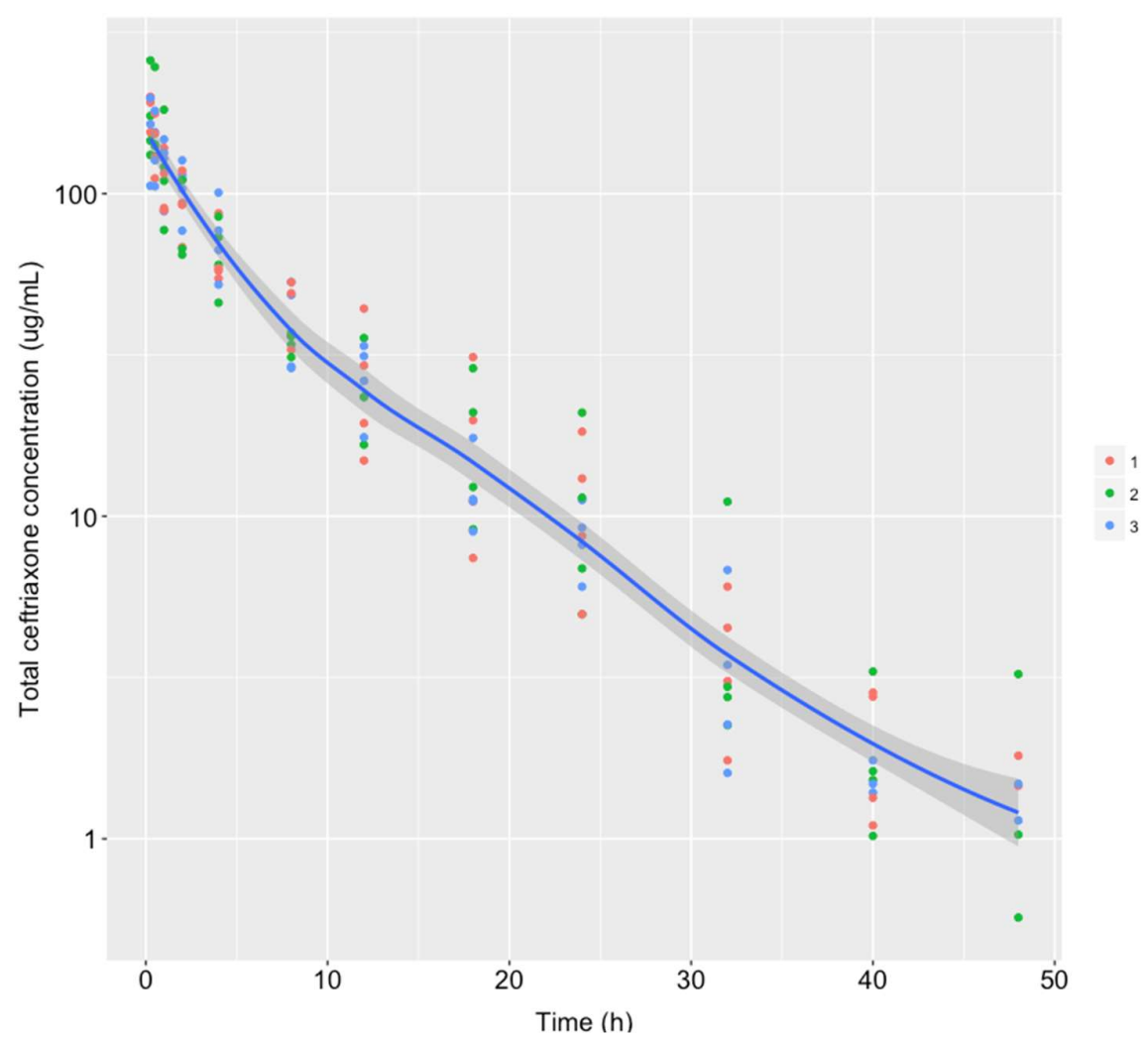

Figure 5. Plasma concentration versus time of ceftriaxone in healthy volunteers $(n=12)$ treated with single IV dose of $1 \mathrm{~g}$ ceftriaxone. The graph represents the mean and $95 \%$ confidence interval (CI) for the data. (1) Volunteers treated only with ceftriaxone, (2) volunteers treated with ceftriaxone and $25 \mathrm{mg}$ of eltrombopag, (3) volunteers treated with ceftriaxone and $50 \mathrm{mg}$ of eltrombopag

Table 3. Parameters validation of the analytical methods of total and unbound plasma ceftriaxone concentrations.

\begin{tabular}{|c|c|c|}
\hline & Total ceftriaxone & Unbound ceftriaxone \\
\hline \multicolumn{3}{|l|}{ Absolute recovery $(\%)$} \\
\hline $2.4 \mu \mathrm{g} / \mathrm{mL}$ & 117 & --- \\
\hline $160 \mu \mathrm{g} / \mathrm{mL}$ & 106 & --- \\
\hline Linearity $(\mu \mathrm{g} / \mathrm{mL})$ & $1-200$ & $1-200$ \\
\hline Linear equation & $y=0.005 x+0.001$ & $y=0.006 x+0.001$ \\
\hline Coefficient of determination & $r^{2}=0.99$ & $r^{2}=0.99$ \\
\hline Limit of quantification $(\mu \mathrm{g} / \mathrm{mL})$ & 1.0 & 1.0 \\
\hline Precision $(\mathrm{CV} \%, \mathrm{n}=5)$ & 16.4 & 14.0 \\
\hline Accuracy (Inaccuracy \%) & 2.8 & 0.2 \\
\hline \multicolumn{3}{|l|}{ Intra-assay precision (CV \%) } \\
\hline $2.4 \mu \mathrm{g} / \mathrm{mL}(\mathrm{n}=5)$ & 9.0 & 6.9 \\
\hline $80 \mu \mathrm{g} / \mathrm{mL}(\mathrm{n}=5)$ & 9.3 & 1.9 \\
\hline $160 \mu \mathrm{g} / \mathrm{mL}(\mathrm{n}=5)$ & 10.5 & 3.9 \\
\hline \multicolumn{3}{|l|}{ Inter-assay precision (CV \%) } \\
\hline $2.4 \mu \mathrm{g} / \mathrm{mL}(\mathrm{n}=15)$ & 9.6 & 13.6 \\
\hline $80 \mu \mathrm{g} / \mathrm{mL}(\mathrm{n}=15)$ & 13.8 & 13.2 \\
\hline $160 \mu \mathrm{g} / \mathrm{mL}(\mathrm{n}=15)$ & 14.3 & 5.4 \\
\hline \multicolumn{3}{|l|}{ Intra-assay accuracy, $\%$} \\
\hline $2.4 \mathrm{pg} / \mathrm{mL}(\mathrm{n}=5)$ & -14.1 & -4.9 \\
\hline $80 \mathrm{pg} / \mathrm{mL}(\mathrm{n}=5)$ & -4.5 & 12.7 \\
\hline $160 \mathrm{pg} / \mathrm{mL}(\mathrm{n}=5)$ & 9.3 & 14.6 \\
\hline \multicolumn{3}{|l|}{ Inter-assay accuracy, $\%$} \\
\hline $2.4 \mu \mathrm{g} / \mathrm{mL}(\mathrm{n}=15)$ & -4.3 & -4.9 \\
\hline $80 \mu \mathrm{g} / \mathrm{mL}(\mathrm{n}=15)$ & -2.8 & 12.7 \\
\hline $160 \mathrm{pg} / \mathrm{mL}(\mathrm{n}=15)$ & -2.5 & 14.6 \\
\hline
\end{tabular}


Table 4. Anthropometric characteristics of the investigated healthy volunteers $(n=12)$. Data are expressed as mean $(95 \% \mathrm{CI})$.

\begin{tabular}{lccc}
\hline & $\begin{array}{c}\text { eltrombopag } 0 \mathrm{mg} \\
\mathrm{n}=4)\end{array}$ & $\begin{array}{c}\text { eltrombopag } 25 \mathrm{mg} \\
(\mathrm{n}=4)\end{array}$ & $\begin{array}{c}\text { eltrombopag } 50 \mathrm{mg} \\
(\mathrm{n}=4)\end{array}$ \\
\hline Sex $\mathrm{m} / \mathrm{f}$ & $2 / 2$ & $2 / 2$ & $2 / 2$ \\
Age $($ years $)$ & 28 & 28 & 35 \\
& $(20-35)$ & $(27-32)$ & $(28-43)$ \\
Weight $(\mathrm{kg})$ & 70 & 76 & 73.1 \\
& $(52-87)$ & $(54-97)$ & $(53.9-92.2)$ \\
Height $(\mathrm{m})$ & 1.69 & 1.73 & 1.69 \\
& $(1.59-1.78)$ & $(1.61-1.85)$ & 25.0 \\
BMI $\left(\mathrm{kg} / \mathrm{m}^{2}\right)$ & 24.1 & 24.8 & $(21.5-28.5)$ \\
& $(20.2-28.0)$ & $(21.0-28.6)$ & 110 \\
Creatinine clearance & 120 & 122 & $(86-134)$ \\
$\left(\mathrm{mL} / \mathrm{min} / 1.73 \mathrm{~m}^{2}\right)^{*}$ & $(93-146)$ & $(106-139)$ & 4.35 \\
Serum albumin & 4.28 & 4.35 & $(4.22-4.48)$ \\
$(\mathrm{g} / \mathrm{dL})$ & $(4.13-4.42)$ & $(4.22-4.48)$ &
\end{tabular}

Table 5. Total ceftriaxone pharmacokinetics in healthy volunteers $(n=12)$ treated with single IV dose of $1 \mathrm{~g}$ of the drug according to eltrombopag association. Values are expressed as mean $(95 \% \mathrm{CI})$.

\begin{tabular}{lccc}
\hline Parameter & Eltrombopag & Eltrombopag & Eltrombopag \\
& $0 \mathrm{mg}$ & $25 \mathrm{mg}$ & $50 \mathrm{mg}$ \\
\hline $\mathrm{Cmax}(\mu \mathrm{g} / \mathrm{mL})$ & 207 & 207 & 170 \\
& $(124-290)$ & $(129-285)$ & $(122-217)$ \\
$\mathrm{AUC}^{0-\infty}(\mu \mathrm{g} . \mathrm{h} / \mathrm{mL})$ & 1106 & 1083 & 1072 \\
& $(811-1400)$ & $(876-1290)$ & $(872-1273)$ \\
$\mathrm{t}_{1 / 2}(\mathrm{~h})$ & 8.3 & 8.3 & $(5.1-11.1)$ \\
& $(6.8-9.8)$ & $(6.3-10.2)$ & 6.3 \\
$\mathrm{Vd}_{\mathrm{c}}(\mathrm{L})$ & 5.5 & 5.3 & $(4.2-8.5)$ \\
& $(2.9-8.0)$ & $(3.4-7.1)$ & 8.8 \\
$\mathrm{Vd}$ & 9.3 & 9.2 & $(6.0-11.6)$ \\
$\mathrm{MRT}(\mathrm{L})$ & $(6.6-12.0)$ & $(6.6-11.8)$ & 8.98 \\
& 9.9 & 9.9 & $(7.7-10.3)$ \\
$\mathrm{Cl}(\mathrm{L} / \mathrm{h})$ & $(8.1-11.6)$ & $(6.4-13.4)$ & 1.0 \\
$\mathrm{Unbound}(\%)$ & 1.0 & 1.0 & $(0.7-1.2)$ \\
\end{tabular}

ANOVA complemented with the Tukey post-test, $\mathrm{p}<0.05$ (Eltrombopag 0mg vs Eltrombopag $25 \mathrm{mg}$ ) e Eltrombopag $0 \mathrm{mg}$ vs Eltrombopag $50 \mathrm{mg}$ ).

\section{DISCUSSION}

The primary aim of the study was to clinically evaluate previous in vitro study predictions that oral eltrombopag acts as an inhibitor of intestinal BCRP but not hepatic BCRP (6). To test this question the pharmacokinetics of intravenous ceftriaxone (a predominately BCRP and MRP2 substrate) $(18,19,25)$ was followed in healthy volunteers in the absence versus presence of therapeutic oral doses $(25$ or $50 \mathrm{mg})$ of eltrombopag.
Sensitive, selective and reproducible LCMS/MS methods for the quantitation of total ceftriaxone from $50 \mu \mathrm{L}$ of plasma and unbound ceftriaxone from $100 \mu \mathrm{L}$ of plasma were developed and validated. The methods are suitable for pharmacokinetic and therapeutic drug monitoring studies up to 48 hours after the administration of a single dose of $1 \mathrm{~g}$ intravenous ceftriaxone. A previous LC-MS/MS reported by Ongas et al. (2017) reported volumes of $350 \mu \mathrm{L}$ plasma for the quantification of total and unbound ceftriaxone 
(26). Lefeuvre et al. (2017) reported an LC-MS/MS method for quantification of total ceftriaxone in plasma samples using plasma volumes of $100 \mu \mathrm{L}$ (27). Then, the small volumes of plasma used in the present study represents an important advantage, in special for pediatric studies.

One of the first studies to investigate the pharmacokinetics of ceftriaxone in adults was performed by Patel et al. (24). The authors reported the use of three single doses of ceftriaxone $(0.5,1$ and $2 \mathrm{~g}$ ) in a 30-min intravenous infusion in 12 healthy adult volunteers, with serial blood collections up to 24 hours after ceftriaxone infusion. The pharmacokinetic parameters reported by the authors at a dose of $1 \mathrm{~g}$ were similar to those obtained in the present study (Table 5), with the harmonic mean elimination half-life of $6 \mathrm{~h}$, a mean AUC of $1006 \mu \mathrm{g} . \mathrm{h} / \mathrm{mL}$, a Vd of $9 \mathrm{~L}$ and a $\mathrm{Cl}$ of 1 $\mathrm{L} / \mathrm{h}$. Pollock et al. reported single dose and multiple dose pharmacokinetic parameters of ceftriaxone in healthy adult volunteers (28). The average pharmacokinetic parameters in the first dose were: $\mathrm{Cl} 1.057 \mathrm{~L} / \mathrm{h}, \mathrm{Vd} 9.66 \mathrm{~L}_{\text {and }} \mathrm{t}_{1 / 2} 6.4 \mathrm{~h}$. Payasi et al. evaluated the pharmacokinetics of ceftriaxone and sulbactam in 8 healthy adult volunteers. The results were also similar to those of the present study, revealing an average Cmax of $152.06 \mu \mathrm{g} / \mathrm{mL}$, a t $\mathrm{t}_{1 / 2}$ of $5.2 \mathrm{~h}$ and an $\mathrm{AUC}_{0-24}$ of $760.16 \mu \mathrm{g} . \mathrm{h} / \mathrm{mL}$ (29).

The pharmacological activity of antibiotics depends on the unbound fraction in plasma and consequently, the concentration at the site of infection (30). The present study shows that the unbound ceftriaxone fraction in adults ranged from 6 to $13 \%$ (Table 5), which is similar to values reported in the literature (31-33). Stoeckel et al. reported that the binding of ceftriaxone to plasma proteins in adults ranged from 4 to $16.7 \%$ and was concentration-dependent (34). Popick et al. reported that ceftriaxone is highly bound to plasma proteins $(95.3 \%)$ at a low plasma concentration (25 $\mu \mathrm{g} / \mathrm{mL}$ ) and decreased to $64.2 \%$ as the concentration was increased to $800 \mu \mathrm{g} / \mathrm{mL}$ (35). Schaad \& Stoeckel quantified the unbound fraction of ceftriaxone in infants and children receiving intravenous ceftriaxone at a dose of $50 \mathrm{mg} / \mathrm{kg}$, and the mean result was that $15.8 \pm 0.03 \%$ of the ceftriaxone fraction was unbound to plasma proteins in infants, and $16.4 \pm 0.03 \%$ was unbound to plasma proteins in children (36).

The inclusion of 4 volunteers in each group resulted in a significance level of $p<0.05$, a test power of $80 \%$ and a difference between AUC means of at least $30 \%$ (ceftriaxone vs. ceftriaxone $+25 \mathrm{mg}$ eltrombopag or ceftriaxone $+50 \mathrm{mg}$ eltrombopag). So, this difference of $30 \%$ in AUC is significant in clinical research studies and it is considered a high difference in the pharmacokinetic studies by U.S. Food and Drug Administration (37).

Although the lack of eltrombopag plasma concentrations remain as a limitation in this study, therapeutic doses of eltrombopag (two doses of 25 or $50 \mathrm{mg}$ administered $28 \mathrm{~h}$ and $4 \mathrm{~h}$ before intravenous ceftriaxone administration) did not alter the pharmacokinetics of ceftriaxone in healthy volunteers, suggesting that the eltrombopag does not inhibit hepatic BCRP. Thus, the results of our clinical study are in agreement with the in vitro results reported by Elsby et al. (2016) regarding eltrombopag as an inhibitor of only intestinal BCRP (6). Rosuvastatin exposure was higher (AUC by $55 \%$ and Cmax by $103 \%$ ) in healthy volunteers following eltrombopag administration (75 mg po daily for 5 days) (9) and rosuvastatin exposure was also higher (AUC by 1.96-fold and Cmax by 1.88 -fold) in healthy volunteers following fostamatinib administration (100 $\mathrm{mg}$ po twice daily for 5 days) due to intestinal BCRP inhibition.

\section{CONCLUSIONS}

The results do not support the existence of significant clinical pharmacokinetic drug interaction involving hepatic BCRP in human subjects receiving intravenous ceftriaxone $(1 \mathrm{~g})$ and oral eltrombopag. possibly due to the lack of inhibition of hepatic BCRP by eltrombopag. Clinically, intravenously administered BCRP substrate drugs including ceftriaxone should not require dose adjustments in subjects taking oral eltrombopag.

\section{ACKNOWLEDGEMENTS}

The authors thank the Fundação de Amparo à Pesquisa do Estado de São Paulo (FAPESP, 2014/06526-7) and the Conselho Nacional de Desenvolvimento Científico e Tecnológico (CNPq) for financial support.

\section{CONFLICT OF INTEREST}

The authors report no conflicts of interest related to this work.

\section{REFERENCES}

1. Giacomini KM, Huang S-M, Tweedie DJ, Benet LZ, Brouwer KLR, Chu X, et al. Membrane transporters in drug development. Nat Rev Drug Discov, 2010;9:215-36. DOI:10.1038/nrd3028.

2. Mao Q, Unadkat JD. Role of the breast cancer resistance protein (BCRP/ABCG2) in drug transport--an update. AAPS J, 2015;17:65-82. DOI:10.1208/s12248-014-9668-6. 
3. Maliepaard M, Scheffer GL, Faneyte IF, Gastelen A Van, Pijnenborg ACLM. Subcellular Localization and Distribution of the Breast Cancer Resistance Protein Transporter in Normal Human Tissues Subcellular Localization and Distribution of the Breast Cancer Resistance Protein Transporter in Normal Human Tissues 1. Cancer Res, 2001;61:3458-64.

4. Keskitalo JE, Zolk O, Fromm MF, Kurkinen KJ, Neuvonen PJ, Niemi M. ABCG2 polymorphism markedly affects the pharmacokinetics of atorvastatin and rosuvastatin. Clin Pharmacol Ther, 2009;86:197-203. DOI:10.1038/clpt.2009.79.

5. Giacomini KM, Balimane P V., Cho SK, Eadon M, Edeki T, Hillgren KM, et al. International transporter consortium commentary on clinically important transporter polymorphisms. Clin Pharmacol Ther, 2013;94:23-6. DOI:10.1038/clpt.2013.12.

6. Elsby R, Martin P, Surry D, Sharma P, Fenner K. Solitary Inhibition of the Breast Cancer Resistance Protein Efflux Transporter Results in a Clinically Significant Drug-Drug Interaction with Rosuvastatin by Causing up to a 2-Fold Increase in Statin Exposure. Drug Metab Dispos, 2016;44:398408. DOI:10.1124/dmd.115.066795.

7. Kruijtzer CMF, Beijnen JH, Rosing H, ten Bokkel Huinink WW, Schot M, Jewell RC, et al. Increased Oral Bioavailability of Topotecan in Combination With the Breast Cancer Resistance Protein and PGlycoprotein Inhibitor GF120918. J Clin Oncol, 2002;20:2943-50. DOI:10.1200/JCO.2002.12.116.

8. Breedveld P, Zelcer N, Pluim D, Sönmezer O, Tibben MM, Beijnen JH, et al. Mechanism of the pharmacokinetic interaction between methotrexate and benzimidazoles: potential role for breast cancer resistance protein in clinical drug-drug interactions. Cancer Res, 2004;64:5804-11. DOI:10.1158/00085472.CAN-03-4062.

9. Allred AJ, Bowen CJ, Park JW, Peng B, Williams $\mathrm{DD}$, Wire MB, et al. Eltrombopag increases plasma rosuvastatin exposure in healthy volunteers. $\mathrm{Br} \mathrm{J}$ Clin Pharmacol, 2011;72:321-9. DOI:10.1111/j.1365-2125.2011.03972.x.

10. Takeuchi K, Sugiura T, Matsubara K, Sato R, Shimizu T, Masuo Y, et al. Interaction of novel platelet-increasing agent eltrombopag with rosuvastatin via breast cancer resistance protein in humans. Drug Metab Dispos, 2014;42:726-34. DOI:10.1124/dmd.113.054767.

11. Iida S, Kawanishi T, Hayashi M. Indications for a ceftriaxone dosing regimen in Japanese paediatric patients using population pharmacokinetic/pharmacodynamic analysis and simulation. J Pharm Pharmacol, 2011;63:65-72. DOI:10.1111/j.2042-7158.2010.01179.x.

12. Gergs U, Clauss T, Ihlefeld D, Weiss M, Pönicke K, Hofmann GO, et al. Pharmacokinetics of ceftriaxone in plasma and bone of patients undergoing hip or knee surgery. J Pharm Pharmacol, 2014;66:1552-8. DOI:10.1111/jphp.12282.

13. Li N, Zhou X, Yuan J, Chen G, Jiang H, Zhang W.
Ceftriaxone and acute renal failure in children. Pediatrics, 2014;133:e917-22. DOI:10.1542/peds.2013-2103.

14. Nahata MC, Barson WJ. Ceftriaxone: a thirdgeneration cephalosporin. Drug Intell Clin Pharm 1985;19:900-6.

15. Russo $\mathrm{T}$ a, Cook S, Gorbach SL. Intramuscular ceftriaxone in home parenteral therapy. Antimicrob Agents Chemother, 1988;32:1439-40. DOI:10.1128/AAC.32.9.1439.

16. Patel IH, Chen S, Parsonnet M, Hackman MR, Brooks MA, Konikoff J, et al. Pharmacokinetics of ceftriaxone in humans. Antimicrob Agents Chemother, 1981;20:634-41.

17. Perry T, Schentag JJ. Clinical use of ceftriaxone: a pharmacokinetic-pharmacodynamic perspective on the impact of minimum inhibitory concentration and serum protein binding. Clin Pharmacokinet, 2001;40:685-94.

18. Brogard JM, Jehl F, Paris-Bockel D, Sini F, Blickle JF, Adloff M, et al. Ceftriaxone, a cephalosporin with high hepatic elimination. Evaluation of its biliary clearance in man. Therapeutic value. Schweiz Med Wochenschr, 1987;117:1549-59.

19. Kato Y, Takahara S, Kato S, Kubo Y, Sai Y, Tamai $\mathrm{I}$, et al. Involvement of multidrug resistanceassociated protein 2 (Abcc2) in molecular weightdependent biliary excretion of beta-lactam antibiotics. Drug Metab Dispos, 2008;36:1088-96. DOI:10.1124/dmd.107.019125.

20. Lee S, Kim SK, Lee DY, Chae SY, Byun Y. Pharmacokinetics of a new, orally available ceftriaxone formulation in physical complexation with a cationic analogue of bile acid in rats. Antimicrob Agents Chemother, 2006;50:1869-71. DOI:10.1128/AAC.50.5.1869-1871.2006.

21. Bussel JB, Cheng G, Saleh MN, Psaila B, Kovaleva L, Meddeb B, et al. Eltrombopag for the Treatment of Chronic Idiopathic Thrombocytopenic Purpura. N Engl J Med, 2007;357:2237-47. DOI:10.1056/NEJMoa073275.

22. Guidance for Industry Bioanalytical Method Validation 2001.

23. Dupont WD, Plummer WD. PS power and sample size program available for free on the internet. Control Clin Trials, 1997;18:274.

24. Patel IH, Chen S, Parsonnet M, Brooks MA, Konikoff J. Pharmacokinetics of ceftriaxone in humans . Antimicrob Agents Chemother, 1981;20:634-41.

25. Stoeckel K, Koup JR. Pharmacokinetics of ceftriaxone in patients with renal and liver insufficiency and correlations with a physiologic nonlinear protein binding model. Am J Med, 1984;77:26-32.

26. Ongas M, Standing J, Ogutu B, Waichungo J, Berkley JA, Kipper K. Liquid chromatography-tandem mass spectrometry for the simultaneous quantitation of ceftriaxone, metronidazole and hydroxymetronidazole in plasma from seriously ill, severely malnourished children. Wellcome Open Res, 2017;2:43. DOI: 10.12688/wellcomeopenres.11728.2. 
27. Lefeuvre S, Bois-Maublanc J, Hocqueloux L, Bret L, Francia T, Eleout-Da Violante C, Billaud EM, Barbier F, Got L. A simple ultra-highperformance liquid chromatography-high resolution mass spectrometry assay for the simultaneous quantification of 15 antibiotics in plasma. J Chromatogr B Analyt Technol Biomed Life Sci, 2017;1065-1066:50-8. DOI: 10.1016/j.jchromb.2017.09.014.

28. Pollock AA, Tee PE, Patel IH, Spicehandler J, Simberkoff MS, Rahal JJ. Pharmacokinetic characteristics of intravenous ceftriaxone in normal adults. Antimicrob Agents Chemother, 1982;22:816-23.

29. Payasi A, Chaudhary M, Gupta A, Dwivedi VK, Bhatnagar A. Pharmacokinetic study of sulbactomax. J Toxicol Sci, 2010;35:459-64. DOI: $10.2131 /$ jts.35.459.

30. Briscoe SE, McWhinney BC, Lipman J, Roberts JA, Ungerer JPJ. A method for determining the free (unbound) concentration of ten beta-lactam antibiotics in human plasma using high performance liquid chromatography with ultraviolet detection. J Chromatogr B Analyt Technol Biomed Life Sci, 2012;907:178-84. DOI:10.1016/j.jchromb.2012.09.016.

31. Popick AC, Crouthamel WG, Bekersky I. Plasma protein binding of ceftriaxone. Xenobiotica, 1987; 17:1139-45.

DOI:10.3109/00498258709167406.

32. Stoeckel K, McNamara PJ, Brandt R, PlozzaNottebrock H, Ziegler WH. Effects of concentration-dependent plasma protein binding on ceftriaxone kinetics. Clin Pharmacol Ther, 1981;29:650-7.

33. Schaad UB, Stoeckel K. Single-dose pharmacokinetics of ceftriaxone in infants and young children. Antimicrob Agents Chemother, 1982;21:248-53.

34. Stoeckel K, McNamara PJ, Brandt R, PlozzaNottebrock H, Ziegler WH. Effects of concentration-dependent plasma protein binding on ceftriaxone kinetics. Clin Pharmacol Ther, 1981;29:650-7.

35. Popick AC, Crouthamel WG, Bekersky I. Plasma protein binding of ceftriaxone. Xenobiotica, 1987; 17:1139-45.

DOI: $10.3109 / 00498258709167406$.

36. Schaad UB, Stoeckel K. Single-dose pharmacokinetics of ceftriaxone in infants and young children. Antimicrob Agents Chemother, 1982;21:248-53.

37. Davit BM, Conner DP, Fabian-Fritsch B, Haidar SH, Jiang X, Patel DT, et al. Highly Variable Drugs: Observations from Bioequivalence Data Submitted to the FDA for New Generic Drug Applications. AAPS J, 2008;10:148-56. DOI:10.1208/s12248008-9015-X. 